\title{
Role of UPFC in Power Flow Control of Distribution Line
}

\author{
Nitin Pawar ${ }^{1}$, C. Veeresh ${ }^{2}$ \\ ${ }^{1}$ M.tech Scholar, EE Department, MIT, Mandsaur \\ ${ }^{2}$ Assistant Professor, EE Department, MIT, Mandsaur
}

\begin{abstract}
In this paper the performance of Unified Power Flow Controller (UPFC) is investigated in controlling the flow of power over the transmission line. The technology of power system utilities around the world has rapidly evolved with considerable changes in the technology along with improvements in power system structures and operation. The ongoing expansions and growth in the technology, demand a more optimal and profitable operation of a power system with respect to generation, transmission and distribution systems. Power quality is an issue that is becoming increasingly important to electricity consumers at all levels of usage. Sensitive equipment and non-linear loads are commonplace in both the industrial and the domestic environment; because of this a heightened awareness of power quality is developing [2].
\end{abstract}

Keywords: FACTS, UPFC, Power Quality

\section{Introduction}

The power-transfer capability of long transmission lines are usually limited by large signals ability. Economic factors, such as the high cost of long lines and revenue from the delivery of additional power, give strong incentives to explore all economically and technically feasible means of raising the stability limit. On the other hand, the development of effective ways to use transmission systems at their maximum thermal capability has caught much research attention in recent years. Fast progression in the field of power electronics has already started to influence the power industry. This is one direct outcome of the concept of flexible ac transmission systems (FACTS) aspects, which has become feasible due to the improvement realized in power-electronic devices. In principle, the FACTS devices could provide fast control of active and reactive power through a transmission line. The unified power-flow controller (UPFC)is a member of the FACTS family with very attractive features. This device can independently control many parameter, so it is the combination of the properties of a static synchronous compensator (STATCOM) and static synchronous series compensator (SSSC) [1]

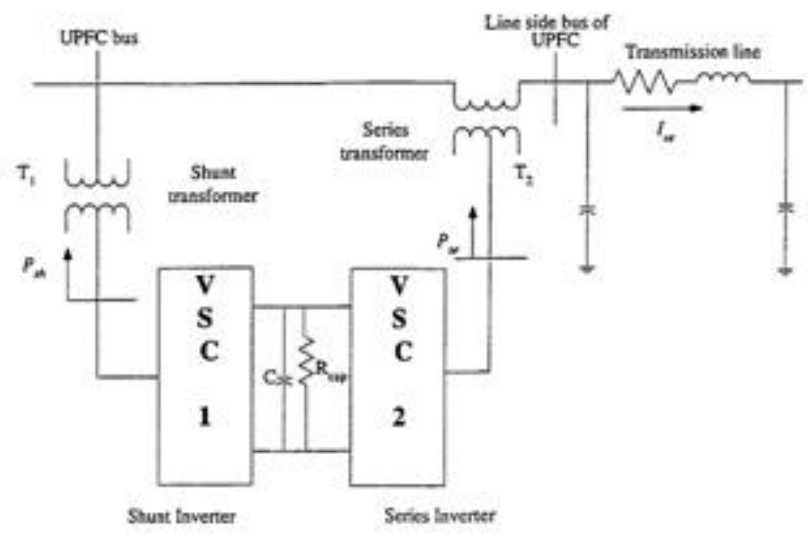

Figure 1.1: UPFC constructions.
The conversion from DC voltage to AC voltage is obtained by using standard bridge circuits. These bridge circuits use GTO as their building blocks. Since these circuits convert $\mathrm{DC}$ voltage to $\mathrm{AC}$ voltage, they are termed as voltage source converters (VSC). The control system associated with VSC allows it to adjust its magnitude and phase angle. The term "inverter" has also been used to denote the VSC.

Consider now the connection of two VSC connected back to back with a common DC Link capacitor ' $\mathrm{C}$ ' as shown in Fig. 1.1. Such an arrangement allows for all the three functions namely series, shunt and phase angle compensation to be unified in one unit. Inverter 1 is connected to a shunt transformer and the inverter 2 is connected to a series transformer. It is readily seen that the VSC connected to the shunt transformer can perform the function of a variable reactive power source similar to that of shunt compensator. In addition, the inverter 1 can charge the DC link capacitor. Inverter 2 can provide series or phase angle compensation by injecting a series voltage of proper phase relationship. In the case of series compensation, inverter 2 can function independent of the inverter 1, as inverter 2 supplies/consumes only reactive power and does not have any real power exchange with invener 1 . In such a case. the DC link capacitor voltage will ideally be constant

\section{UPFC Modeling}

\subsection{Load Flow Models}

Different load flow models have been used to mode1 the UPFC in varying degree of complexity and have been discussed here briefly. As mentioned in chapter-1, a UPFC consists of two inverters connected back to back with a DC link capacitor. One inverter is connected in shunt and the other in series with the transmission line as shown in Fig.1.2. The early modelling efforts for a UPFC were focussed on the series inverter modelling. The reason being that commercial software did not have series voltage source models. American Electric Power (AEP) and Westinghouse came up with a load flow model [8]. The requirement for the inclusion of the model was that the Load flow should be a 


\section{International Journal of Science and Research (IJSR) \\ ISSN (Online): 2319-7064}

Index Copernicus Value (2013): 6.14 | Impact Factor (2014): 5.611

solved one. Basically, what was required was that the voltages and the angles of the power system buses had to be known in advance to inchde the UPFC model. The Load flow model for UPFC consisted of two generators, one representing the shunt inverter and the other the series inverter. Different configurations of these generators were needed to model different operating conditions. Fig.1.3 shows the model that was used to include the UPFC into Load flow studies [8]. Here the process of solving starts with the opening of the series line, and the generator $G 2$ generates the scheduled real and reactive power. The scheduled power in the transmission line is converted into an equivalent load at the terminal where the generator $\mathrm{G} 1$ is connected. The generator $\mathrm{G} 1$ generates the required reactive power to maintain scheduled bus voltage.

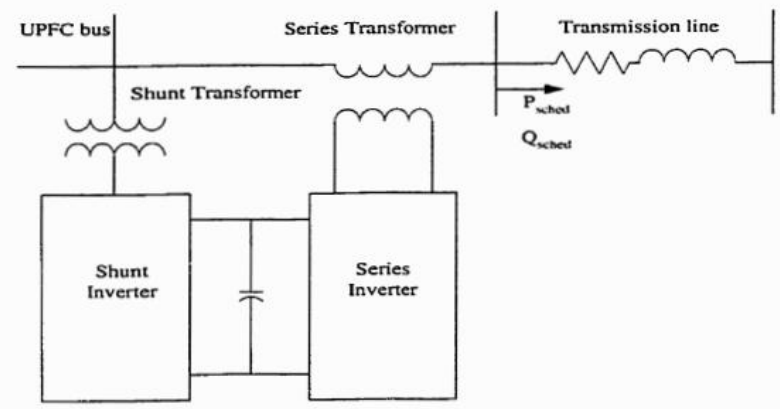

Figure 1.2: A UPFC connected to a Transmission line.

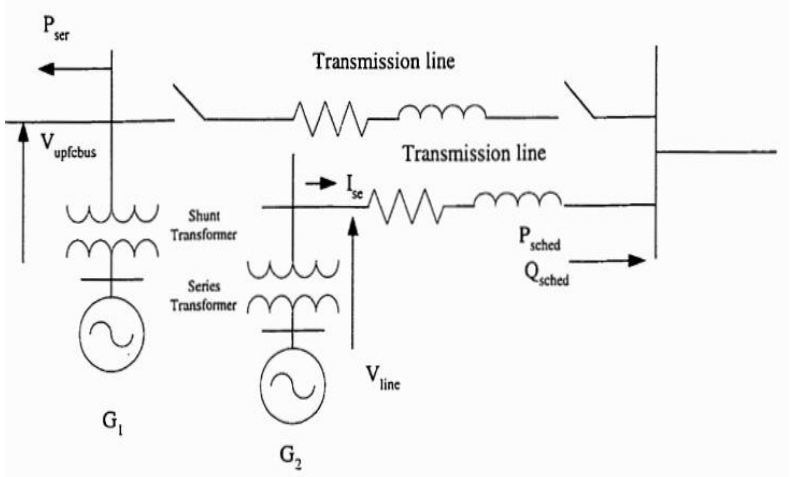

Figure 1.3: Coupled source mode1 for UPFC

Generator G2 also supplies the real power demand of the series inverter. The series injected voltage is the phase difference between $V_{\text {line }}$ and $V_{\text {upfcus }}$. The product of series injected voltage and the current $I_{s e}$ gives the amount of voltampere of the series inverter. The real part of the voltampere $\left(P_{\text {ser }}\right)$ of the series inverter is added as a load at the shunt inverter bus. The algorithm to perform the addition of equivalent loads at the shunt inverter bus, to open the appropriate lines, have been included in their program. The problem is that it needs a solved load £low case. The idea of solving a load flow with an UPFC is to obtain the shunt and the series inverters' injected voltages for a given operating condition. This procedure is crude for solving a load flow with UPFC.

\subsection{Dynamic Model}

The dynamic model for a UPFC is cantered round the dynamics of the DC link capacitor. It is well known that the DC link capacitor dynamics is a function of the series and the shunt inverter control variables. The need for including the DC link capacitor dynamics while conducting dynamic studies arises from the fact that it provides the link between the series and the shunt inverter operation in terms of real power balance. Exchange of real power between the series injected voltage by the series inverter and the transmission line current causes the DC link capacitor voltage to either increase or decrease depending on the direction of real power exchange between them. The decrease/increase of the DC link capacitor voltage is sensed by the shunt inverter which absorbs/supplies the necessary real power through the shunt transformer to regulate the DC link capacitor voltage. The models present in the literature Vary on the basis of the mode1 used for the shunt and series inverter.

\section{Introduction to FACTS Devices}

Flexible transmission system is akin to high voltage dc and related thyristors developed designed to overcome the limitations of the present mechanically controlled ac power transmission system. Use of high speed power electronics controllers, gives 5 opportunities for increased efficiency[12].

1) Greater control of power so that it flows in the prescribed transmission routes.

2) Secure loading (but not overloading) of transmission lines to levels nearer their required limits.

3) Greater ability to transfer power between controlled areas, so that the generator reserve margin- typically 18 $\%$ may be reduced to $15 \%$ or less.

4) Prevention of cascading outages by limiting the effects of faults and equipment failure.

5) Damping of power system oscillations, which could damage equipment and or limit usable transmission capacity.

Flexible system requires tighter transmission control and efficient management of inter-related parameters that constrains today's system including -

1) Series impedance- phase angle.

2) Shunt impedance- occurrence of oscillations at various frequencies below rated frequency.

3) This results in transmission line to operate near its thermal rating. Eg- a $1000 \mathrm{kv}$ line may have loading limit $3000-4000 \mathrm{Mw}$.but the thermal limit may be $5000 \mathrm{Mw}[1]$.

4) SVC- Uses thyristor valves to rapidly add or remove shunt connected reactors and or capacitors often in coordination with mechanically controlled reactors and/or capacitors.

5) NGH-SSR damper- a resonance damper:- A thyristor acswitch connected in series with a small inductor and resistor across the series capacitor[1].

6) Statcon (static condenser):- A 3 phase inverter that is driven from voltage across a dc storage capacitor and whose there output voltages are in phase with the ac system voltage. when the output voltages are higher or lower than the ac system voltage the current flow is caused to lead or lag and difference in voltage amplitudes determine how much current flows[2]. Reactive power and its polarity can be controlled by controlling voltage.

7) Phase Angle Regulator:-The phase shift is accomplished by adding or subtracting a variable voltage concept that is perpendicular to the phase voltage of the line 


\section{International Journal of Science and Research (IJSR) \\ ISSN (Online): 2319-7064}

Index Copernicus Value (2013): 6.14 | Impact Factor (2014): 5.611

8) Unified power control :- In this concept an ac voltage vector generated by a thyristor based inverter is injected in series with phase voltage. The driving dc voltage for inverter is obtained by rectifying the ac to dc from the same transmission line. In such an arrangement the injected voltage may have any phase angle relationship to the phase voltage. It is possible to obtain a net phase and amplitude voltage change that confers control of both active and reactive power[5].

9) Dynamic Brake :- A shunt connected resistive load, controlled by thyristor switches. such a load can be selectively applied in each pass, half cycle by half cycle to damp any specific power flow oscillation, so that generating unit run less risk of losing synchronism, as a result more can be transferred over systems subjected to stability constraints.

\section{Advantages of TCR in FACT}

1) Accuracy of compensation-Very good

2) Control flexibility-Very good

3) Reactive power capacity- Lagging or leading indirect

4) Control - Continuous

5) 5 Response Time- Fast, 0.5 to 0.2 cycles

6) Harmonics- Very high(Large size filters are needed)

7) Losses- Good but increase in lagging mode

8) Phase balancing ability- good

9) Cost-moderate

\section{Conclusion}

Voltage, active power, reactive power with UPFC and without UPFC will be studied and compared. When the transmission line is without UPFC, the real and reactive power flow cannot be controlled. Transmission capability of existing transmission line is highly improved with the presence of UPFC. But the difference between the sending end real power and receiving end real power is high in the transmission line with UPFC. This is due to increase in transmission losses, which include losses in both converters and coupling transformers.

The modeling of UPFC and analysis of power systems embedded with UPFC has been presented, which is capable of solving large power networks very reliably with the UPFC.

\section{References}

[1] Ali Ajami, S.H. Hosseini and G.B. Gharehpetian, "Modelling and Controlling of UPFC for Power System Transient Studies", ECTI Transactions on Electrical Engineering Electronics, and Communications, vol.- 5, no-2, pp. 29-35, Aug 2007.

[2] C. Benachaiba and M. L. Doumbia, "Enhancement of Power Quality by Using Power Quality Equipment", Mediamira Science Publisher, vol.-51, no.2, pp. 104108, 2010.

[3] S. Muthukrishnan and A. Nirmal Kumar, "Comparison of Simulation and Experimental Results of UPFC used for Power Quality Improvement", International Journal of Computer and Electrical Engineering, vol.- 2, no. 3, pp. 555-559, June 2010.

[4] Narain G. Hingorani and Laszlo Gyugyi, "Understanding FACTS: Concepts and Technology of Flexible AC Transmission Systems”, ISBN 0-78033455-8, New York: IEEE Press, 2000.

[5] Roger C. Dugan, Mark. F. McGranaghan, Surya Santoso and H. Wayne Beaty "Electrical Power Systems Quality”, Third Edition, ISBN 978-0-07176156-7, The McGraw Hill Companies, Inc.

[6] Amit Shiwalkar and N.D.Ghawghawe, "Power Flow Control Through Transmission Line with UPFC to Mitigate Contingency", International Journal of Advanced Electrical and Electronics Engineering (IJAEEE), vol-1, issue-2, pp. 59-64, 2012.

[7] M.E.C. Vidyasagar and S. Ravindra, "FACTS Devices, UPFC with Extended DC Link", International Conference on Electrical and Electronics Engineering, pp. 148-152, June 2012.

[8] K. Manoz Kumar Reddy, "Simulation of Real, Reactive Power and Regulation With UPFC", International Journal of Scientific and Research Publications, vol.- 2, issue 4, pp. 1-4, April 2012.

[9] Nashiren.F. Mailah and Senan M. Bashi, "Single Phase Unified Power Flow Controller (UPFC): Simulation and Construction", European Journal of Scientific Research, vol.-30, no. 4, pp.677-684, 2009.

[10]Arup Ratan Bhowmik and Champa Nandi, "Implementation of Unified Power Flow Controller (UPFC) for Power Quality Improvement in IEEE 14Bus System", International Journal of Computer Technology Applications, vol.- 2(6), pp. 1889-1996, Nov - Dec 2011.

[11] T. Nireekshana, Dr. G. Kesava Rao \& Dr. S. Siva Naga Raju, "Modelling and Control Design of Unified Power Flow Controller for Various Control Strategies", International Journal of Engineering Science and Technology, vol.- 2(11), pp. 6293-6307, 2010.

[12] L. Y. Dong, L. Zhang and M. L. Crow, "A New Control Strategy for the Unified Power Flow Controller", Power Engineering Society Winter Meeting, 2002. IEEE vol-1, pp. 562-566, Jan 2002.

[13] S. Muthukrishnan and A. Nirmalkumar, "Comparison and Simulation of Open Loop System and Closed Loop System Based UPFC Used for Power Quality Improvement", International Journal of Soft Computing and Engineering (IJSCE), vol.- 1, issue 6, pp. 253-258, Jan 2011.

[14] CH. Chengaiah, R.V.S. Satyanarayana \& G.V. Marutheswar, "Study on Effect of UPFC Device in Electrical Transmission System: Power Flow Assessment", International Journal of Electrical and Electronics Engineering (IJEEE), vol-1, iss-4, pp. 6670,2012 . 